\title{
Ocular hyperperfusion following onset of intensified insulin therapy is inversely correlated with plasma endothelin-1 in Type I diabetes
}

\author{
G. Fuchsjäger-Mayrl'1, A. Kautzky-Willer ${ }^{2}$, B. Kiss ${ }^{3}$, M. Roden ${ }^{2}$, O. Wagner ${ }^{4}$, J. Pleiner ${ }^{1}$, M. Wolzt ${ }^{1}$, \\ L. Schmetterer ${ }^{1,5}$ \\ ${ }^{1}$ Department of Clinical Pharmacology, ${ }^{2}$ Department of Internal Medicine III/Endocrinology and Metabolism, ${ }^{3}$ Department \\ of Ophthalmology, ${ }^{4}$ Department of Medical and Chemical Laboratory Diagnostics \\ ${ }^{5}$ Institute of Medical Physics, University of Vienna, Vienna, Austria
}

\section{Abstract}

Aims/hypothesis. It has been reported that improvement of metabolic control by intensified insulin therapy in patients with Type I (insulin-dependent) diabetes mellitus is associated with alterations in ocular blood flow. We hypothesized that these changes in ocular blood flow could be associated with alterations of plasma insulin, glucose or endothelin concentration.

Methods. In 16 patients with Type I diabetes ocular haemodynamic parameters were assessed daily during the first 5 days of institution of intensified insulin therapy and plasma concentrations of glucose, insulin, and endothelin-1 plasma were measured. Retinal white blood cell flux was estimated with the blue field entoptic technique. Pulsatile choroidal blood flow was assessed by laser interferometric measurement of fundus pulsation amplitude.

Results. Retinal white blood cell flux $(p=0.0015)$ and ocular fundus pulsation amplitude $(p<0.001)$ increased during institution of strict metabolic control. Changes in ocular haemodynamic variables were inversely correlated with concentrations of plasma ET-1, but not with that of insulin or glucose.

Conclusions/interpretation. These data indicate that institution of improved metabolic status is paralleled by rapid changes in the production of ET-1, which could in turn affect ocular perfusion. [Diabetologia (2002) 45:883-889]

Keywords Ocular blood flow, strict metabolic control, blue field entoptic technique, laser interferometry, fundus pulsation.
The Diabetes Control and Complications Trial (DCCT) demonstrated a reduction in the development and progression of the long-term complications of Type I diabetes with intensive insulin therapy

Received: 15 November 2001 / Revised: 11 January 2002

Published online: 1 May 2002

C) Springer-Verlag 2002

Corresponding author: L. Schmetterer, Department of Clinical Pharmacology, Währinger Gürtel 18-20, A-1090 Vienna, Austria, University of Vienna, Vienna, Austria, e-mail: Leopold.Schmetterer@univie.ac.at

Abbreviations: DCCT, Diabetes Control and Complications Trial; WBCF, Retinal white blood cell flux; SBP, systolic blood pressure; DBP, diastolic blood pressure; MAP, mean blood pressures; ET-1, endothelin-1; WBCD, number of white blood cells; WBCV, mean flow velocity of white blood cells; $\lambda$, wavelength; $\Delta_{\mathrm{N}(\mathrm{t})}$, variation of the interference order; $\Delta_{(\mathrm{t})}$ changes in optical distance; FPA, fundus pulsation amplitude aimed to achieve glycaemic control as close as possible to the non-diabetic range [1]. Moreover, the DCCT showed that total lifetime exposure to glycaemia is the principal determinant of the risk of retinopathy [2]. However, shortly after the institution of strict diabetic control some patients show progression of diabetic retinopathy $[1,3]$. Previous studies indicate that this progression of diabetic retinopathy is associated with changes in retinal blood flow $[4,5$, 6].

The reasons for these immediate changes in retinal blood flow and their role in the development of retinopathy are not clear. On the one hand alterations in concentrations of plasma insulin and plasma glucose could affect ocular vascular tone, because insulin and glucose induce vasodilation at the level of the ocular vasculature $[7,8,9,10,11,12]$. Alternatively the institution of strict metabolic control could exert effects 
Table 1. Patients characteristics

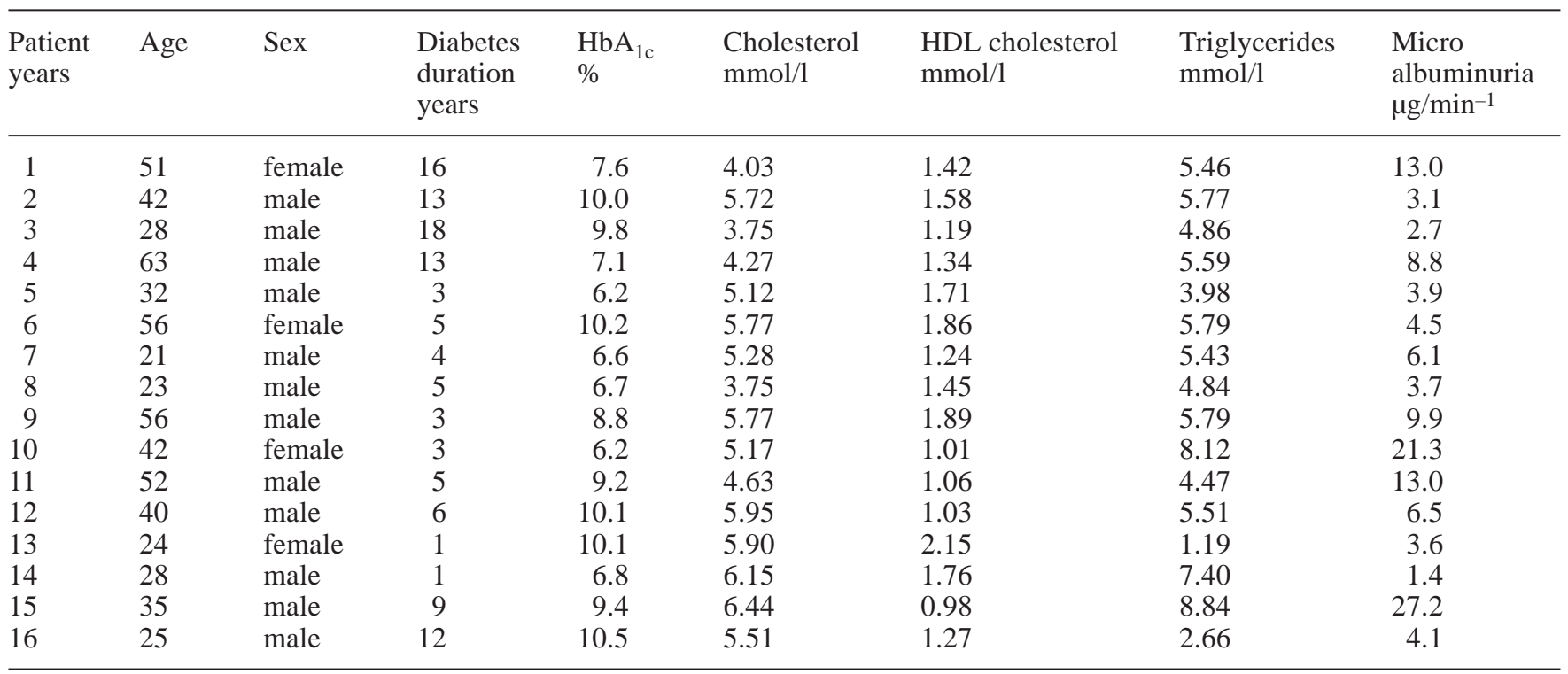

on the vascular endothelium, a key regulator of choroidal and retinal blood flow $[13,14]$.

In this prospective study, we measured ocular haemodynamics during the first 5 days of the institution of strict glycaemic control by intensified insulin therapy. Glucose, insulin and endothelin-1 plasma concentrations were quantified. Retinal white blood cell flux (WBCF) was measured by the blue field entoptic technique [15]. Pulsatile choroidal blood flow was assessed by laser interferometric measurement of fundus pulsation amplitude [16].

\section{Subjects and methods}

Subjects. The study protocol was approved by the ethics committee of the Vienna University School of Medicine. The investigation conforms with the principles outlined in the Declaration of Helsinki and was conducted according to the GCP guidelines. The nature of the study was explained to all subjects, who gave their written consent. Twelve male and four female patients with Type I diabetes (age range 21 to 66 years, means \pm SD: $39 \pm 15$ ), scheduled for initiation of intensified insulin therapy, were recruited (Table 1). Inclusion criteria were Type I diabetes with no or mild non-proliferative retinopathy and an age of more than 19 years. The sample size calculation was based on the day-to-day reproducibility of blue field entoptic technique in our laboratory (unpublished observation). Using an $\alpha$-error of 0.05 and a beta-error of 0.80 we calculated a total number of 13 patients to allow for detection of a $20 \%$ change in retinal white blood cell flux. Changes smaller than that were considered clinically irrelevant. To allow for a dropout rate of $20 \%$, a total of 16 patients were included in this study.

Exclusion criteria were secondary diabetes mellitus (druginduced, cystic fibrosis, etc.), maturity onset diabetes of the young (MODY diabetes), untreated hypertension (defined as systolic blood pressure $>150 \mathrm{mmHg}$, diastolic blood pressure $>90 \mathrm{mmHg}$ ), previous participation in an intensified insulin treatment program, presence of intraocular pathology other than diabetic retinopathy, and previous laser photocoagulation treatment. Subjects characteristics are given in Table 1.

In addition, a healthy age-matched control group (mean age \pm SD: $39 \pm 14$ years) was studied. Neither of these subjects had any sign of ocular pathology as shown from a routine ophthalmological examination.

Study design. Only patients, who were hospitalised for intensified insulin therapy, participated in this open prospective study. All patients included underwent an ambulatory programme to improve metabolic control before entering the study. Grading of diabetic retinopathy was done according to the modified Airlie House classification [17, 18, 19]. Baseline ocular blood flow measurement was done on the day of hospitalisation. In all subjects, the right eye was studied. Thereafter a regimen of strict diabetic control of blood glucose was started. During the subsequent 5 days ocular haemodynamic measurements were made every day. At each time point systemic blood pressure, heart rate, and plasma concentrations of glucose, insulin and ET-1 were determined after a resting period of 20 minutes in sitting position.

Healthy control subjects were studied only once after a light breakfast in the morning. The measurement procedures consisted of the same techniques as in the diabetic group.

Study methods. Systolic, diastolic and mean blood pressures (SBP, DBP, MAP) were measured on the upper arm by an automated oscillometric device (HP-CMS patient monitor, Hewlett Packard, Palo Alto, Calif., USA). Pulse rate was automatically recorded from a finger pulse-oxymetric device (HP-CMS patient monitor).

Plasma insulin and glucose concentrations, $\mathrm{HbA}_{1 \mathrm{c}}$, cholesterol, high density lipoproteines and triglycerides were measured by routine laboratory procedures. Urinary albumin was measured by turbidimetry on a Hitachi 717 analyser (Boehringer Mannheim, Mannheim, Germany) from a 24-h urine example. Microalbuminuria was expressed as albumin excretion rate $\left(\mu \mathrm{g} \cdot \mathrm{min}^{-1}\right)$. ET-1 plasma concentrations were determined using a commercially available RIA (endothelin kit Peninsula RIK 6901, Penninsula Laboratories, San Carlos, Calif., USA) after 
Sep Pak C18 extraction [20]. The sensitivity of the RIA was $0.2 \mathrm{fmol}$ at $90 \%$ binding and the intra- and interassay coefficients of variation were less than $8 \%$. The cross-reactivity is $17 \%$ with human big endothelin-1, $7 \%$ with endothelin-2 and -3 and below the detection limit with human atrial natriuretic peptide and with angiotensin II.

Retinal WBCF was assessed with the blue field entoptic technique (Oculix Sarl, Arbaz, Switzerland). This non-invasive method has been previously described [15]. The blue field entoptic phenomenon can best be seen by looking into a blue light with a narrow optical spectrum at a wavelength of approximately $430 \mathrm{~nm}$. Under these conditions tiny corpuscles can be seen flying around quickly in an area of 10 to 15 degrees of arc radius centred at the fovea. Probably this phenomenon is caused by the fact that red, but not white, blood cells absorb short wavelength light. Thus, the passage of a white blood cell is perceived as a flying corpuscle. For determination of retinal haemodynamic parameters, a simulated particle field is shown to the subjects under study. By making comparisons with their own entoptic observation, subjects can adjust the number of white blood cells (WBCD) and the mean flow velocity (WBCV). Retinal WBCF is then calculated as the product of WBCD and WBCV. Each measurement consisted of at least five matching tests, and the means of velocity and density were calculated. Only values with an SD of less than $20 \%$ were accepted as accurate. Because this depends on the skill of the volunteers, subjects who did not reach a SD of less than $20 \%$ at any matching trial during the study were excluded from data analysis.

Pulse synchronous pulsations of the eye fundus were assessed by laser interferometry on the subject's right eye as described previously [16]. Briefly, the eye is illuminated by the beam of a single mode laser diode with a wavelength $(\lambda)$ of $783 \mathrm{~nm}$. The parallel laser light is focussed to the fovea providing a laser spot of about $50 \mu \mathrm{m}$ in diameter. The light is reflected at both the surface of the cornea and the retina. The two re-emitted waves produce interference fringes from which the distance changes between cornea and retina during a cardiac cycle can be calculated. Distance changes between cornea and retina lead to a corresponding variation of the interference or$\operatorname{der}(\Delta \mathrm{N}(\mathrm{t}))$. This change in interference order can be evaluated by counting the fringes moving inwards and outwards during the cardiac cycle. Changes in optical distance $(\Delta \mathrm{L}(\mathrm{t}))$, corresponding to the cornea-retina distance changes, can then be calculated by using the formula $\Delta \mathrm{L}(\mathrm{t})=\Delta \mathrm{N}(\mathrm{t}) \cdot \lambda / 2$. The maximum distance change is called the fundus pulsation amplitude (FPA) and estimates the local pulsatile blood flow [21]. FPA was calculated as the mean of at least five cardiac cycles. To obtain information on the choroidal blood flow, the macula, where the retina lacks vasculature, was chosen for measurements [22].

Data analysis. All statistical analyses were done using the Statistica software package (Release 4.5, StatSoft, Tulsa, Ok., USA). Effects of institution of strict metabolic control on all outcome variables were assessed by ANOVA for repeated measurements. Post-hoc analysis was done using paired $t$ tests and Bonferronis correction for multiple comparisons. ET-1 plasma concentrations could affect systemic blood pressure, which could in turn affect ocular perfusion pressure. We therefore also calculated $p$ values by a covariance analysis using the mean arterial pressure as a covariate. Ocular and systemic haemodynamic changes were expressed as percentage change from baseline. Changes in plasma concentrations were expressed as the absolute difference versus baseline levels. The association between changes in ocular haemodynamic parameters and changes in the other parameters was investigated using a linear correlation analysis for each subject. Accordingly, the number of calculated correlation coefficients exactly matched the number of participating subjects. The median of the correlation coefficients was calculated and a Wilcoxon-signed rank test was applied to test for statistical significance. Outcome variables between patients with diabetes and healthy control subjects were compared with unpaired $t$ tests. Data are presented as means \pm SEM.

\section{Results}

The diabetic retinopathy of the 16 patients included in our study was graded according to the modified Airlie House classification. Eleven patients had no evidence of diabetic retinopathy. Five of the 16 patients presented with haemorrhages and/or microaneuryisms graded as $1 \mathrm{a}$ in fields 3 to 8 . One patient also had hard exsudates graded as $1 \mathrm{a}$ in fields 3 to 8 . No other le-
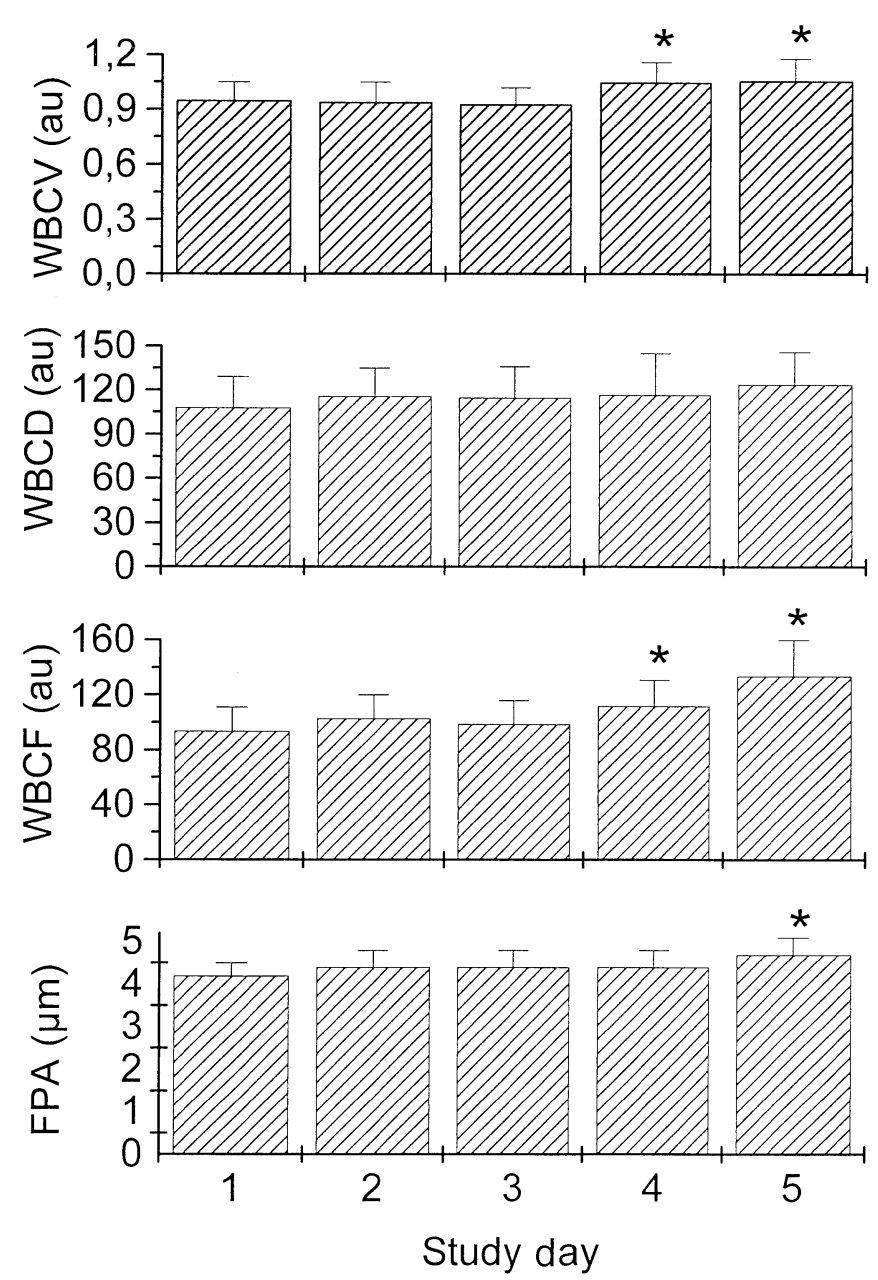

Fig. 1. Effects of intensified insulin therapy on white blood cell flux (WBCF), white blood cell velocity (WBCV) and white blood cell density (WBCD) measured by the blue field entoptic technique $(n=13)$ and fundus pulsation amplitude (FPA; $n=16)$. Values are expressed as means \pm SEM. $* p<0.05$ vs baseline as assessed with repeated measure ANOVA and post-hoc comparison using paired $t$ tests for and Bonferronis correction 
Table 2. Blood pressures and pulse rates during the 5 study days

\begin{tabular}{lrrrrr}
\hline & Day 1 & Day 2 & Day 3 & Day 4 & Day 5 \\
\hline Systolic blood pressure (mmHg) & $134 \pm 5$ & $132 \pm 4$ & $125 \pm 4$ & $130 \pm 4$ & $128 \pm 3$ \\
Diastolic blood pressure (mmHg) & $75 \pm 4$ & $71 \pm 3$ & $70 \pm 3$ & $70 \pm 3$ & $69 \pm 3$ \\
Pulse rate (beats/min) & $73 \pm 3$ & $81 \pm 3$ & $78 \pm 3$ & $76 \pm 3$ & $79 \pm 3$ \\
\hline
\end{tabular}

$n=16$; means \pm SEM

Table 3. Glucose, insulin and endothelin-1 plasma concentrations at the start and at the end of the study

\begin{tabular}{lcc}
\hline & Day 1 & Day 5 \\
\hline Glucose, (mmol/l) & $8.3 \pm 0.7$ & $8.0 \pm 0.8$ \\
Insulin, (pmol/1) & $125 \pm 24$ & $121 \pm 18$ \\
Endothelin-1, (pmol/l) & $3.6 \pm 0.2$ & $3.1 \pm 0.2$ \\
\hline
\end{tabular}

$n=16$; means \pm SEM

sions were observed in fields 3 to 8 . In fields 1 and 2 no patient showed any sign of diabetic retinopathy.

Thirteen of the 16 included patients were able to fulfil the reproducibility criteria for the blue field entoptic technique on all 5 study days. The WBCF data of the three patients who did not provide adequate results were not included for analysis. The FPA could be measured in all subjects and all data were included for analysis.

The results of ocular haemodynamic measurements are presented in Figure 1. All retinal haemodynamic parameters continuously increased during the 5 days observation period. This effect was significant for WBCV (ANOVA: $p=0.021$ ) and WBCF (ANOVA: $p=0.0015$ ), but not for WBCD (ANOVA: $p=0.46$ ). On average retinal $\mathrm{WBCF}$ was $36 \pm 11 \%$ higher on the $5^{\text {th }}$ day after the start of institution of strict metabolic control as compared to baseline. Fundus pulsation amplitude also increased during the 5-day observation period (ANOVA: $p=0.018$ ). The increase in FPA on day 5 of the study was $9 \pm 4 \%$ compared with baseline. The result of the covariance analysis was very similar to what we have calculated from the ANOVA analysis (WBCV: $p=0.017$; WBCF: $p=0.0009$; WBCD: $p=0.37$; FPA: $p=0.017$ ), indicating that changes in ocular perfusion pressure due to altered ET-1 were not responsible for the changes in ocular haemodynamic parameters.

Neither systemic blood pressure nor pulse rate changed during the period of strict metabolic control (Table 2). Plasma glucose and plasma insulin concentrations were comparable on the study days at the time points when ocular haemodynamics were measured. Data for the baseline day and day 5 are presented in Table 3. Plasma ET-1 concentrations tended to decrease during the period of strict metabolic control (Table 3), but this effect was not significant.

Changes in FPA correlated inversely with changes in plasma ET-1 concentrations (Table 4). The individual correlation coefficients were in the range of -0.92
Table 4. Individual correlation coefficients between changes in endothelin-1 plasma concentrations and changes in retinal white blood cell flux (WBCF) and fundus pulsation amplitude, respectively

\begin{tabular}{lcc}
\hline Patient number & WBCF & FPA \\
\hline 1 & - & -0.88 \\
2 & -0.84 & -0.46 \\
3 & 0.14 & -0.54 \\
4 & -0.75 & -0.28 \\
5 & -0.73 & -0.92 \\
6 & -0.83 & 0.22 \\
7 & -0.71 & 0.50 \\
8 & -0.20 & 0.74 \\
9 & -0.97 & -0.83 \\
10 & -0.79 & -0.94 \\
11 & - & -0.61 \\
12 & - & -0.04 \\
13 & -0.82 & 0.18 \\
14 & -0.92 & -0.05 \\
15 & -0.33 & -0.89 \\
16 & -0.85 & -0.46 \\
\hline
\end{tabular}

and 0.50 (Median: $r=-0.46 ; \quad p=0.030$ ). Similarly, changes in plasma ET-1 were inversely correlated with retinal WBCF with correlation coefficients in the range of -0.97 and 0.14 (Median: $r=-0.79 ; p=0.002$ ). By contrast, neither plasma insulin nor plasma glucose concentrations were associated with any of the ocular haemodynamic parameters (data not shown).

In the healthy control group plasma concentrations of glucose were in the normal range $(5.1 \pm 0.2 \mathrm{mmol} / \mathrm{l}$, $p<0.001$ vs patients with diabetes). Plasma concentrations of insulin were comparable to those observed in the diabetic patients $(111 \pm 21 \mathrm{pmol} / \mathrm{l})$. Plasma concentrations of ET-1 were consistently lower in healthy controls than in patients with Type I diabetes $(2.3 \pm 0.1 \mathrm{pmol} / \mathrm{l} ; p<0.001)$. Parameters obtained with the blue field entoptic technique were not significantly different from those observed in diabetic patients. Retinal $\mathrm{WBCF}$ in healthy subjects $(119 \pm 15 \mathrm{AU})$ was slightly higher than WBCF in diabetic subjects at day 1 and slightly lower than the value observed in the patients at day 5. However, none of these effects reached the level of significance. FPA in healthy subjects $(4.1 \pm 0.4)$ was comparable to FPA in diabetic subjects at day 1 . However, at day 5 the FPA value was significantly higher in patients with Type I diabetes than in healthy control subjects $(p=0.021)$. 


\section{Discussion}

In this study, a significant increase in retinal WBCF and ocular FPA was observed during the first 5 days of institution of strict metabolic control in patients with Type I diabetes. This change in retinal and choroidal haemodynamic parameters correlated with a reduction in plasma ET-1 concentrations. By contrast, changes in ocular blood flow were not associated with actual plasma glucose and insulin.

Changes in retinal perfusion have been reported to be associated with the progression of diabetic retinopathy $[4,5,6]$. Using the blue field entoptic technique, authors reported that the WBCF was higher in those eyes which showed progression of diabetic retinopathy after 6 months of intensified insulin treatment, compared with those eyes that showed no progression. In addition, authors reported that the institution of strict metabolic control was associated with a $16 \%$ increase in WBCV at day 5 [6]. This is compatible with our results, although our study was not designed to investigate which eyes show progression of diabetic retinopathy. Neither WBCF at day 1 nor WBCF at day 5 was significantly different from the normal in our study. There are contradictory findings regarding the level of retinal perfusion in patients with diabetes [23, $24,25,26,27]$. Our study was not designed to answer the question whether patients after institution of strict metabolic control have higher WBCF but our results are compatible with the idea that ocular perfusion abnormalities play a role in the development and progression of diabetic retinopathy. By contrast, FPA at day 5 was significantly higher in patients with Type I diabetes compared with healthy control subjects. This indicates choroidal hyperperfusion at the fifth day after institution of strict metabolic control. Whether FPA returns to normal values thereafter remains to be established.

This study suggests that changes in plasma ET-1 contribute to the short-term ocular haemodynamic changes during institution of intensified insulin therapy. Endothelins have been displayed in isolated tissue samples of the retina and the choroid [28, 29] and specific binding sites are present in the eye [30, 31]. Animal [31, 32, 33, 34] and human [35, 36] studies have shown that exogenous administration of ET-1 markedly decreases ocular perfusion. Our data corroborate previous findings that ET-1 plays a role in the pathogenesis of diabetic vascular complications including diabetic retinopathy [37]. Evidence for an altered endothelin system in the eyes of animals with experimental diabetes arises from previous studies. In streptozotocin (STZ)-induced diabetic rats a blunted response to intravitreal ET-1 is observed in the retinal vasculature [33]. Retinal ET-1 and ET-receptor mRNA expression is increased in another rat model of Type I diabetes compared to normal controls [38] an observation in keeping with findings in the STZ- induced diabetes model in rats in which a twofold increase in preproET-1 messenger RNA was observed [34].

This study suggests that very soon after the institution of strict metabolic control changes in the release of endothelium-derived vasoactive substances occur. There is evidence from previous studies that Type I diabetes is associated with endothelial dysfunction $[39,40]$ and our data indicate that an imbalance in the release of vasoactive substances from the endothelium could be influenced by the treatment regimen. The reason for this reduced ET-1 release, which could in turn influence ocular perfusion, is not known. It has, however, been shown that insulin and glucose exert ocular haemodynamic effects $[7,8,9,10,41]$, which are additive [12]. Moreover, both, insulin and glucose could alter the expression of ET-1 in ocular tissues. In the STZ-induced diabetic rat insulin treatment for 10 days leads to a fourfold increase of ET-1 in ocular tissues [42]. On the other hand hyperglycaemia increases ET-1 expression in cultured endothelial cells, but the mechanism is not fully understood [43]. The complex interactions between insulin and glucose that alter the release of ET-1 during institution of strict metabolic control and in turn affect ocular blood flow remain to be established. In addition, changes in other metabolic factors during institution of intensified insulin treatment such as non-esterified fatty acids could influence the level of ocular perfusion [44].

In this study, we observed higher plasma ET-1 concentrations in patients with Type I diabetes. This has been reported in some [45, 46], but not in all studies [47]. Hence, institution of intensified insulin treatment normalises ET-1 plasma concentrations. Whether strict metabolic control restores physiological ET-1 plasma concentrations in the long term is, however, not clear or if WBVF and FPA decreases again after some time following the onset strict metabolic control. Obviously ET-1 is not the only factor that controls ocular blood flow in patients with diabetes during institution of strict metabolic control. On the one hand the correlation coefficient between changes in plasma ET-1 and changes in retinal and choroidal blood flow parameters were not equal to one. More importantly, WBCF was not significantly different between groups although healthy control subjects had significantly lower ET-1 plasma concentrations. This clearly indicates that other hitherto unidentified factors control ocular blood flow in diabetic patients.

In conclusion, our data indicate an early increase in ocular blood flow during institution of strict metabolic control, which is negatively correlated to changes in plasma ET-1 concentrations. This establishes ET-1 as an important determinant of ocular blood flow in Type I diabetes and indicates that the release of endothelium-derived vasoactive substances in these patients could strongly depend on the treatment regimen. 


\section{References}

1. The Diabetes Control and Complication Trial Research Group (1993) The effect of intensive treatment of diabetes on the development and progression of long term complications in insulin-dependent diabetes mellitus. N Engl J Med 329:977-986

2. The Diabetes Control and Complication Trial Research Group (1995) The relationship of glycaemic exposure (HbA1c) to the risk of development and progression of retinopathy in the diabetes control and complications trial. Diabetes 44:968-983

3. Lauritzen T, Frost-Larsen K, Larsen HW, Deckert T (1983) Effects of 1 year of near-normal glucose levels on retinopathy in insulin-dependent diabetics. Lancet i:200-204

4. Grunwald JE, Brucker AJ, Schwartz SS et al. (1990) Diabetic glycaemic control and retinal blood flow. Diabetes 39:602-607

5. Grunwald JE, Brucker AJ, Braunstein SN et al. (1994) Strict metabolic control and retinal blood flow in diabetes mellitus. Br J Ophthalmol 78:598-604

6. Grunwald JE, Riva CE, Petrig BL, Brucker AJ, Schwartz SS, Braunstein SN, DuPont J, Grunwald S (1995) Strict control of glycaemia: effects on blood flow in the large retinal vessels and in the macular microcirculation. $\mathrm{Br} \mathrm{J}$ Ophthalmol 79:735-741

7. Grunwald JE, Riva CE, Martin DB, Quint AR, Epstein PA (1987) Effect of an insulin-induced decrease in blood glucose on the human diabetic retinal circulation. Ophthalmology 94:1614-1620

8. Sullivan PM, Davies GE, Caldwell G, Morris AC, Kohner EM (1990) Retinal blood flow during hyperglycemia. A laser Doppler velocimetry study. Invest Ophthalmol Vis Sci 31:2041-2045

9. Su EN, Yu DY, Alder VA, Cringle SJ, Yu PK (1996) Direct vasodilatory effect of insulin on isolated retinal arterioles. Invest Ophthalmol Vis Sci 37:2634-2644

10. Schmetterer L, Müller M, Fasching P et al. (1997) Renal and ocular haemodynamic effects of insulin. Diabetes 46:1868-1874

11. Polak K, Dallinger S, Polska E et al. (2001) Effects of insulin on retinal and pulsatile choroidal blood flow in humans. Arch Ophthalmol 118:55-59

12. Luksch A, Polak K, Matulla B et al. (2001) Glucose and insulin exert additive ocular and renal vasodilator effects on healthy humans. Diabetologia 44:95-103

13. Haefliger IO, Meyer P, Flammer J, Luscher TF (1994) The vascular endothelium as a regulator of the ocular circulation: a new concept in ophthalmology? Surv Ophthalmol 39:123-132

14. Brown SM, Jampol LM (1996) New concepts of regulation of retinal vessel tone. Arch Ophthalmol 114:199-204

15. Riva CE, Petrig BL (1990) Retinal blood flow: laser Doppler velocimetry and blue field simulation technique. In: Masters B (ed) Noninvasive diagnostic techniques in ophthalmology. Springer, New York pp 390-409

16. Schmetterer L, Lexer F, Unfried C, Sattmann H, Fercher AF (1995) Topical measurement of fundus pulsations. Opt Eng 34:711-716

17. The Diabetic Retinopathy Study Group (1981) Report Nr.7 A modification of the Airlie House classification of diabetic retinopathy. Invest Ophthalmol Vis Sci 21:211-226

18 . Early treatment diabetic retinopathy study research group (1991) Grading diabetic retinopathy from stereoscopic color fundus photographs - an extension of the modified Airlie House classification. Ophthalmology 98: 786-806
19. Classification of diabetic retinopathy from fluorescein angiograms (1991) ETDRS report number 11. Early Treatment Diabetic Retinopathy Study Research Group. Ophthalmology 98:807-822

20. Haug C, Voisard R, Lenich A et al. (1996) Increased endothelin release by cultured human smooth muscle cells from atherosclerotic coronary arteries. Cardiovasc Res 31:807813

21. Schmetterer L, Dallinger S, Findl O et al. (1998) Noninvasive investigations of the normal ocular circulation in humans. Invest Ophthalmol Vis Sci 39:1210-1220

22. Schmetterer L, Lexer F, Graselli U, Findl O, Eichler HG, Wolzt M (1996) The effect of different mixtures of O2 and CO2 on ocular fundus pulsations. Exp Eye Res 63:351-355

23. Patel V, Rassam S, Newsom R, Wiek J, Kohner E (1992) Retinal blood flow in diabetic retinopathy. BMJ 305:678683

24. Bursell SE, Clermont AC, Kinsley BT, Simonson DC, Aiello LM, Wolpert HA (1996) Retinal blood flow changes in patients with insulin-dependent diabetes mellitus and no diabetic retinopathy. Invest Ophthalmol Vis Sci 37:886897

25. Grunwald JE, DuPont J, Riva CE (1996) Retinal haemodynamics in patients with early diabetes mellitus. $\mathrm{Br} \mathrm{J}$ Ophthalmol 80:327-331

26. Schmetterer L, Wolzt M (1999) Ocular blood flow and associated functional deviations in diabetic retinopathy. Diabetologia 42:387-405

27. Findl O, Dallinger S, Rami B et al. (2000) Ocular haemodynamics and colour contrast sensitivity in patients with type 1 diabetes. Br J Ophthalmol 84:493-498

28. Stitt AW, Chakravarthy U, Gardiner TA, Archer DB (1996) Endothelin-like immunoreactivity and receptor binding in the choroid and retina. Curr Eye Res 15:111-117

29. Wollensak G, Schaefer HE, Ihling C (1998) An immunohistochemical study of endothelin-1 in the human eye. Curr Eye Res 17:541-545

30. MacCumber MW, D'Anna SA (1994) Endothelin receptorbinding subtypes in the human retina and choroid. Arch Ophthalmol 112:1231-1235

31. Granstam E, Wang L, Bill A (1992) Ocular effects of endothelin-1 in the cat. Curr Eye Res 11:325-332

32. Cioffi GA, Orgul S, Onda E, Bacon DR, Van Buskirk EM (1995) An in vivo model of chronic optic nerve ischemia: the dose-dependent effects of endothelin-1 on the optic nerve microvasculature. Curr Eye Res 14:1147-1153

33. Bursell SE, Clermont AC, Oren B, King GL (1995) The in vivo effect of endothelins on retinal circulation in nondiabetic and diabetic rats. Invest Ophthalmol Vis Sci 36:596607

34. Takagi C, King GL, Takagi H, Lin YW, Clermont AC, Bursell SE (1996) Endothelin-1 action via endothelin receptors is a primary mechanism modulating retinal circulatory response to hyperoxia. Invest Ophthalmol Vis Sci 37:2099-2109

35. Schmetterer L, Findl O, Strenn K et al. (1997) Effects of endothelin-1 (ET-1) on ocular haemodynamics. Curr Eye Res 16:687-692

36. Strenn K, Matulla B, Wolzt M et al. (1998) Reversal of endothelin-1-induced ocular haemodynamic effects by lowdose nifedipine in humans. Clin Pharmacol Ther 63:54-63

37. Hopfner RL, Gopalakrishnan V (1999) Endothelin: emerging role in diabetic vascular complications. Diabetologia 42:1383-1394

38. Chakrabarti S, Gan XT, Merry A, Karmazyn M, Sima AA (1998) Augmented retinal endothelin-1, endothelin-3, endothelin A and endothelinB gene expression in chronic diabetes. Curr Eye Res 17:301-307 
39. Calver A, Collier J, Vallance P (1992) Inhibition and stimulation of nitric oxide synthesis in the human forearm arterial bed of patients with insulin-dependent diabetes. J Clin Invest 90:2548-2554

40. Schmetterer L, Findl O, Fasching P et al. (1997) Nitric oxide and ocular blood flow in patients with IDDM. Diabetes. 46:653-658

41. Atherton A, Hill DW, Keen H, Young S, Edwards EJ (1980) The effect of acute hyperglycaemia on the retinal circulation of the normal cat. Diabetologia 18:233-237

42. Chakravarthy U, Hayes RG, Stitt AW, Douglas A (1997) Endothelin expression in ocular tissues of diabetic and insulin-treated rats. Invest Ophthalmol Vis Sci 38:2144-2151

43. Chen S, Apostolova MD, Cherian MG, Chakrabarti S (2000) Interaction of endothelin-1 with vasoactive factors in mediating glucose-induced increased permeability in endothelial cells. Lab Invest 80:1311-1321
44. Polak K, Schmetterer L, Luksch A et al. (2001) Free fatty acids/triglycerides increase ocular and subcutaneous blood flow. Am J Physiol Regul Integra Comp Physiol 280:R56R61

45. Sarman B, Farkas K, Toth M, Somogyi A, Tulassi Z (2000) Circulating plasma endothelin-1, plasma lipids and complications in Type 1 diabetes mellitus. Diabetes Nutr Metab 13:142-148

46. Takahashi K, Ghatei MA, Lam HC, O'Halloran DJ, Bloom SR (1990) Elevated plasma endothelin in patients with diabetes mellitus. Diabetologia 33:306-310

47. Smulders RA, Stehouwer CD, Olthof CG (1994) Plasma endothelin levels and vascular effects of intravenous L-arginine infusion in subjects with uncomplicated insulin-dependent diabetes mellitus. Clin Sci (Colch) 87:37-43 